\title{
LA CIRCULACIÓN dE LA DOCTRINA EN LA JURISPRUDENCIA CONSTITUCIONAL COLOMBIANA. ANTECEDENTES, TEORÍAS Y CREACIÓN DE UN SISTEMA DE INFORMACIÓN WEB
}

\author{
THE DOCTRINE CIRCULATION IN \\ THE COLOMBIAN CONSTITUTIONAL \\ JURISPRUDENCE. BACKGROUND, \\ THEORIES AND CREATION OF A \\ WEB INFORMATION SYSTEM
}

\author{
Lucio Pegoraro* \\ Liliana Estupiñán Achury** \\ Óscar E. Herrera Bedoya ${ }^{* * *}$ \\ Julio César Gaitán Bohórquez,****
}

Fecha de recepción: 30 de octubre de 2013 Fecha de aprobación: 17 de diciembre de 2013 Disponible en línea: 30 de junio de 2014

\section{Para citar este artículo / To cite this article}

Lucio Pegoraro, Liliana Estupiñán-Achury, Óscar Herrera Bedoya \& Julio César Gaitán Bohórquez, La circulación de la doctrina en la jurisprudencia constitucional colombiana. Antecedentes, teorías y creación de un sistema de información web, 128 Vniversitas Jurídica (2014). http:// dx.doi.org/10.11144/Javeriana.VJ128.cdjc

doi:10.11144/Javeriana.VJ128.cdjc

L. Pegoraro es profesor ordinario de Derecho Público comparado en el Departamento de Ciencia Política y Social de la Universidad de Bolonia. Líder mundial del proyecto de investigación titulado: La circulación del formante doctrinal en la jurisprudencia de las altas cortes. Correo electrónico: luciopegoraro@hotmail.com

** L. Estupiñan Achury es Profesora Titular y Directora del Grupo de Investigación en Derecho Constitucional nacional y comparado de la Facultad de Derecho (Bogotá) de la Universidad Libre; Coordinadora Nacional e investigadora principal del proyecto investigación titulado: La circulación de la doctrina en las Sentencias de la Corte Constitucional colombiana. Doctora en Sociología Jurídica e Instituciones Políticas, Magíster, Especialista en Derecho Constitucional y Administrativo y Abogada de la Universidad Libre. Calle $8^{\text {a No }}$ 5-80 - Centro de Investigaciones Socio Jurídicas. Correo electrónico: lilianaea@hotmail.com

*** O.E. Herrera Bedoya es docente del programa de Ingeniería de Sistemas y Líder de la línea de investigación en Ciencias de la Computación Aplicada del Grupo InnovaTI de la Universidad Piloto de Colombia. Investigador principal del proyecto titulado: la circulación de la doctrina en la jurisprudencia constitucional colombiana. Doctor en Telecomunicaciones, Magister en Comunicación y Desarrollo de Servicios Móviles y Especialista en Proyectos de Ingeniería e Innovación. Carrera 9 \# 45A-44, Bogotá, Colombia (Teléfono: +57 (1) 3322900 Ext. 344). Correo electrónico: oscar-herrera@unipiloto.edu.co.

**** J. C. Gaitán Bohórquez es profesor Asociado, Director del Programa de Doctorado en Derecho y Profesor del Ârea de Derecho Constitucional de la Facultad de Jurisprudencia de la Universidad del Rosario. Investigador asociado del proyecto titulado: la circulación de la doctrina en la jurisprudencia constitucional colombiana. Magíster en Derecho Público de la Universidad Autónoma de Barcelona y Doctor en Evolución de los sistemas jurídicos y nuevos derechos de la Universidad de Lecce - Italia. Correo electrónico: julio.gaitan@urosario. edu.co 


\section{RESUMEN}

El presente artículo surge dentro del marco de una investigación mundial sobre la circulación de la doctrina en la jurisprudencia producida por los tribunales constitucionales y supremos del mundo. Para el caso colombiano, dicha investigación se tradujo en un proyecto dedicado de forma exclusiva al estudio y la circulación del formante doctrinal implícito o explícito en las sentencias de la Corte Constitucional colombiana, aun desde su fecha de creación. Así, el presente artículo da cuenta de los antecedentes académicos de la investigación, marcos teóricos y, de manera especial, presenta un resultado importante para su desarrollo metodológico, esto es, la creación de un sistema de información web compuesto por un software, basado en tecnología de punta de desarrollo propio que permite realizar minería de datos y analizar un universo significativo de sentencias y la correspondiente creación de indicadores importantes para el avance de los estudios socio-jurídicos en torno del papel y la influencia de la doctrina en las sentencias de la Corte Constitucional colombiana.

Palabras clave: jurisprudencia constitucional; minería de datos; circulación de la doctrina; sociología jurídica; gestión del conocimiento; citas 


\section{ABSTRACT}

This article comes within the framework of a global research on the circulation of the doctrine in the jurisprudence produced by the Constitutional and Supreme Courts of the world. For Colombia, the investigation resulted in a project dedicated exclusively to the study and doctrinal formant movement implicit or explicit in the judgments of the Colombian Constitutional Court, ever since its creation date. Thus, this article reports on the academic background of research, theoretical frameworks and, in particular, presents an important result for methodological development, that is, the creation of a Web information system consists of software, based on technology developed in-house that allows data mining and analyzing a significant universe of statements and the corresponding creation of important indicators for advancing socio legal studies about the role and influence of the doctrine in the judgments of the Colombian Constitutional Court.

Keywords: constitutional jurisprudence; data mining; doctrine circulation; legal sociology; knowledge management; references

\section{SUMARIO}

INTRODUCCIÓN.- I. LA CIRCULACIÓN DE LA DOCTRINA EN LA JURISPRUDENCIA. PROBLEMA Y UN ACERCAMIENTO AL MARCO TEÓRICO DE LA INVESTIGACIÓN MUNDIAL.- II. LA CORTE CONSTITUCIONAL COLOMBIANA. PROLIFERACIÓN DE ESTUDIOS SOBRE SU ACTUAR JURISDICCIONAL.- III. UN SISTEMA DE INFORMACIÓN WEB PARA EL ESTUDIO DE LA CIRCULACIÓN DE LA DOCTRINA EN LAS SENTENCIAS DE LA CORTE CONSTITUCIONAL.- A MANERA DE CONCLUSIÓN. 


\section{INTRODUCCIÓN}

El presente artículo surge dentro del marco de una investigación mundial sobre la circulación de la doctrina en la jurisprudencia producida por los tribunales constitucionales y supremos del mundo y cuyo objetivo central es la compenetración del formante doctrinal en las sentencias de los altos tribunales, esto es, el influjo de la doctrina implícita o explícita en los pronunciamientos jurisprudenciales.

En Colombia, dicha investigación mundial se tradujo en la creación de un proyecto de investigación dedicado de forma exclusiva al estudio de este formante en la jurisprudencia de la Corte Constitucional colombiana. El objetivo general de la investigación es estudiar el formante doctrinal tanto explícito como implícito y su incidencia en la creación de la jurisprudencia de la Corte Constitucional colombiana desde su fecha de iniciación.

En desarrollo de dicho objetivo general, la investigación pretende determinar las escuelas, las familias jurídicas y los enfoques teóricos que han marcado la producción jurisprudencial y su correspondiente relación con las sentencias emitidas. Igualmente, identificar a los autores, las editoriales, las universidades y los centros de estudio que mayores insumos han aportado a la creación de la jurisprudencia constitucional colombiana. De la misma forma, la investigación se propone observar la influencia doctrinaria tanto internacional como nacional que ha marcado la creación y los debates dentro de la jurisprudencia constitucional y su nivel de importancia tanto en la parte motiva como decisional.

El desarrollo del proyecto también permitirá periodizar a la Corte Constitucional a partir de la circulación del formante doctrinal. Dicho ejercicio dará a conocer el valor y el uso dado a la doctrina en las diversas cortes o grupos de magistrados; además, la determinación y explicación del momento en que el formante doctrinal pierde valor o importancia en la creación de las sentencias y se posiciona la "doctrina constitucional", el precedente y la tendencia a la cocitación.

El estudio de componente socio-jurídico también permitirá relacionar el origen académico y sociológico de los magistrados, género, estudios, formación, nivel de titulación, regiones de origen, universidades, postulación al cargo, entre otros aspectos, siempre 
y cuando no se vulneren los temas de hábeas data, y cruzar dichos datos con el tema de la doctrina y su circulación en la jurisprudencia de la Corte Constitucional. En todo caso, un esfuerzo académico que permitirá determinar los países que más exportan doctrina jurídica y el nivel de importación en el componente jurisprudencial constitucional colombiano.

El presente artículo, resultado del proyecto de investigación relacionado con el capítulo Colombia, presentará el marco teórico general del proyecto y hará énfasis en el enfoque cuantitativo de la investigación y su primer resultado representado en la creación de un sistema de información web compuesto por un software, basado en tecnología de punta de desarrollo propio que permite realizar minería de datos ${ }^{1}$ e inteligencia de negocio ${ }^{2}$.

Sin duda, es un esfuerzo innovador en el componente metodológico que permite incorporar las Tecnologías de la Información en el ámbito de la investigación jurídica y socio-jurídica, con miras a analizar gran cantidad de información, encontrar correlaciones e indicadores antes no visibles y convertir el conocimiento tácito en explícito de forma científica y documentada.

El sistema de información web alberga datos relacionados con más de 16.000 sentencias proferidas por la Corte Constitucional colombiana desde el año 1992. Mediante la minería de datos se podrá conocer con mayor precisión el influjo del formante doctrinal, las escuelas jurídicas, filosóficas y académicas que circulan en la jurisprudencia objeto de estudio, en la medida en que permite arrojar un sinnúmero de indicadores que permitirán responder preguntas relacionadas con el problema de la investigación y periodizar las tendencias y los enfoques de la Corte Constitucional colombiana en materia doctrinal. ¿Épocas en que más ha citado la Corte Constitucional? ¿Temas o asuntos que requieren de mayor citación doctrinal? ¿Autores más citados y con qué editoriales publican? ¿Cuáles universidades aportan insumos doctrinales? ¿Cuáles son los países y universidades que más influyen en la formación de nuestros magistrados y abundan en las referencias de nuestra jurisprudencia? En fin, una batería de indicadores que solamente es

1 J. Hany \& M. Kamber, Data Mining: Concepts and Techniques, Morgan Kaufmann (2000).

2 L. George, Making Business Intelligence More Useful. Disponible en: http://doi.ieeecomputersociety.org/10.1109/MC.2006.318 (2006). 
posible a partir de la creación y puesta en marcha de la aplicación web que se explica en el presente artículo.

En general, se trata una investigación socio-jurídica que combina diversos métodos para el desarrollo de la pregunta problema y el cumplimiento tanto del objetivo general como de los objetivos específicos del proyecto de investigación. Pluralismo de método parece ser la consigna, para el desarrollo de un proyecto de tamañas pretensiones. En lo posible, se harán alianzas con otras disciplinas científicas como la sociología, la filosofía y la historia, fundamentales a la hora de leer el vasto número de datos que arroja el universo a estudiar.

Así como este artículo presenta el enfoque cuantitativo de la investigación, debe señalarse que el enfoque cualitativo también es fundamental a la hora de estudiar el universo de datos y de entender y comprender a los diversos actores relacionados con la producción de la jurisprudencia constitucional colombiana en los últimos veinte años.

\section{LA CIRCULACIÓN DE LA DOCTRINA EN LA JURISPRUDENCIA. PROBLEMA Y UN ACERCAMIENTO AL MARCO TEÓRICO DE LA INVESTIGACIÓN MUNDIAL}

Como nos recuerda R. C. Van Caenegem (1987) $)^{3}$, desde los albores del actual milenio en el continente europeo los profesores han sido los verdaderos artífices de las grandes construcciones jurídicas. Si bien la codificación les sustrajo del poder de decidir, que antes tenían, también es cierto que pueden desde la academia y los libros comentar, criticar, sistematizar, influir, aconsejar, e incluso muchas veces son nombrados en el Gobierno o el Parlamento, o en las cortes supremas ordinarias, administrativas, o constitucionales. Las sentencias son anónimas, no son los jueces singulares los que producen el derecho, incluso cuando se les permite tener una opinión disidente. No existe una fractura entre academia y formantes dinámicos ${ }^{4}$, sino solo una diversa percepción de los roles.

3 R. C. Van Caenegem, Judges, Legislators and Professors. Chapters in European Legal History, Cambridge University Press, Cambridge (1987).

4 En otras palabras, por "formantes activos" o "dinámicos" se entiende el conjunto de fenómenos 
En Colombia, como en otros países, los profesores se autoperciben como exégetas del derecho legislativo o jurisprudencial, y producen obras donde el derecho por ellos ilustrado es aquel dictado por el legislador o por las cortes (especialmente las constitucionales). A veces, intentan reconstruir los sistemas, ofreciendo interpretaciones o visiones globales (que pueden no tener en cuenta lo que dicen los legisladores y los jueces). Pero en su mayor parte, participan en la producción del derecho, insertándose con sus obras en el debate jurídico en curso, uniformando los formantes y enfatizando de manera análoga a leyes, sentencias y doctrina.

En particular, en el derecho constitucional, legisladores y jueces "usan" (aunque no siempre) a los profesores, y estos hacen referencia a aquellos (siempre). Los profesores lo hacen siempre en modo explícito, en cambio los legisladores y jueces prevalentemente en modo críptico, aunque en ocasiones de manera evidente. En este esquema - muy resumido - los comparatistas tienen una ventaja: los estudiosos del derecho positivo, los legisladores y los jueces nacionales pueden interactuar entre ellos (en distinta medida y con diferente peso de unos respecto de los otros), dentro de cualquier ordenamiento, pero no tienen los instrumentos para interactuar fuera del mismo. Los filósofos, los historiadores, los estudiosos de doctrinas políticas, los teóricos, aseguran la indispensable conexión entre los hechos y su reconstrucción y sistematización. Pero solo los comparatistas aseguran en el formante doctrinal el conocimiento vertical (entre doctrina, legislación y jurisprudencia), como el horizontal (entre un ordenamiento y otro), empezando por los datos positivos - los derechos por lo que son, según la ley, la jurisprudencia y la doctrina-, pero conectándolos y abstrayendo clasificaciones y modelos. Por lo tanto, una vez concluido el trabajo, los que se valen de su obra no son solo los profesores, sino también los formantes dinámicos.

jurídicos - actos o hechos - que directamente producen derecho, que junto con la doctrina (o más en general con la "cultura"), y con otros formantes explícitos o no verbalizados (los criptotipos) concurren a construir los ordenamientos. 
En el marco del debate general (antiguo y todavía vivo) sobre los trasplantes ${ }^{57}$, muchos investigadores han estudiado el uso del derecho comparado en la jurisprudencia: prevalentemente en el campo del derecho civil $^{8}$, pero incluso en el derecho público/constitucional9; también se ha hecho uso del derecho comparado en la legislación, incluso la constitucional y los procesos constituyentes ${ }^{10}$. La sociología jurídica (y los comparatistas), aunque raramente, se ocupa también de las citas de los profesores en las obras doctrinarias ${ }^{11}$.

Entonces, hay obras sobre circulación infra-formantes (legisladores/legisladores, cortes/cortes, doctrina/doctrina); obras interformantes (cortes/legisladores y legisladores/cortes), en particular sobre el uso por parte de las cortes del derecho extranjero en general, inclusivo de leyes y sentencias; sin embargo, nadie estaba ocupado aplicando la verificación empírica de un aspecto particular de la "circulación vertical entre los formantes", es decir, cómo la doctrina afecta al legislador y, a estos efectos, la jurisprudencia.

Un problema de investigación de gran envergadura y que permite estudiar el reasoning de las distintas cortes y tribunales constitucionales, también bajo este particular perfil, para profundizar sobre cómo se forma y se justifica el pensamiento de los jueces (sea en la opinión de la mayoría, sea en concuring o dissenting opinions, donde se admite); verificar si, y en qué modo, el pensamiento de

5 A. Watson, Legal Transplants: An Approach to Comparative Law, Scottish Academic Press, Edimburgh (1974).

6 Según este autor, "If the rules of [...] two countries are already similar [...] it should be no obstacle to their unification or harmonisation that the legal principles involved come ultimately from different sources. [...] It is scholarly law reformers who are deeply troubled by historical factors and habits of thought. Commercial lawyers and business men [...] do not in general perceive differences in habits of thought, but only-and often with irritation-differences in rules".

7 P. Lagrand, The Impossibility of Legal Transplants, Maastricht journ. eur. and comp. Law (1997). Este autor en un famoso artículo niega totalmente la posibilidad de trasplantes, y resalta del papel disuasorio de la cultura, que, a diferencia de las reglas, no puede ser "comprensiblemente" trasplantada, pues cualquier ley en diferentes contextos siempre será una ley diferente.

8 Los libros y artículos más importantes son: Werro (1992), Legeais (1994), Taruffo (1994), Drobnig y Van Erp (1999), Somma (2001), Somma (2004), Canivet, Andenas y Fairgrieve (2004), Markesinis y Fedtke (2009).

9 Entre ellos: Pegoraro (1987), Ponthoreau (1994), Pegoraro \& Damiani (1999), Melin-Soucramanien (2005), Ferrari yy Gambaro (2006), Pegoraro (2006), Pegoraro (2006), Maus (2009), Sagües (2009) y Groppi yy Ponthoreau (2013). En la doctrina anglosajona, sea civilista o sea constitucionalista: L'Heureux-Dubé (1998), Slaughter (2000) y Claes (2012).

10 Por ejemplo: Decaro \& Lupo (2009) y Scaffardi (2011). Acerca las recepciones constitucionales véase por ejemplo: Pegoraro (2003), Fernández (2003) y Pegoraro (2010).

11 Por ejemplo: Markesinis (2004). 
las cortes y de cada uno de los jueces tiene en consideración estudios sobre materias diversas del derecho (como la psicología, la medicina, la antropología, etc.), allí donde la solución de los casos necesita de las aportaciones de ciencias no jurídicas, o de "mediaciones culturales"; además, si son, y cuáles son, las corrientes y las obras de filosofía, doctrina política, teoría general del derecho que explícitamente dan fundamento a una argumentación; razonar sobre la formación jurídica de los jueces constitucionales (al menos allí donde sea posible imputar una referencia doctrinal a un juez específico, lo que no es siempre fácil debido a las decisiones de la mayoría; en particular si existe nexo entre estrato académico, forense, administrativo o político y apertura al derecho extranjero); sobre todo, entender cuáles son los flujos de ideas entre los distintos ordenamientos: quién recibe, quién exporta, cuáles son las doctrinas que se imponen más y de dónde vienen, en relación a qué sectores (en el derecho civil, constitucional, administrativo, penal, etc.); si existe continuidad o no con la historia jurídica de algún país (por ejemplo, cuánto cuenta hoy la doctrina de un país colonizador en un Estado antes colonizado y ahora independiente); en qué medida la barrera lingüística representa un freno a la circulación de las ideas; y, finalmente, desde un perfil práctico, actualizar el ranking de universidades y de escuelas: muchas universidades viven de la fama debida más a una historia antigua y gloriosa que a la efectiva influencia en el pensamiento del mundo globalizado: ¿Por cuánto tiempo será válido este discurso? ¿Cuáles son las universidades emergentes? ¿Y, a nivel individual, son más citados los grandes del pasado, los clásicos, los más recientes o los contemporáneos? ¿Cuáles son (y dónde enseñan) los profesores que mayormente influyen sobre las decisiones de las cortes constitucionales, en los distintos sectores del derecho (además de la filosofía)?

Otras preguntas podrían ser formuladas en el ámbito de la sociología del derecho (por ejemplo, se podría medir la presencia femenina en las citas). Así tendría gran interés un estudio dinámico sobre las transformaciones en la mentalidad de los jueces, o sobre cómo algunas escuelas suplantan a otras en el transcurso del tiempo, y cómo algunos estudiosos se afirman mientras otros son olvidados.

La respuesta a esos interrogantes podría probablemente afirmar la validez de la tesis de la descomposición o separación de los for- 
mantes, propuesta por Sacco y su escuela, y la imposibilidad de leer el derecho comparado en una manera compacta y homogénea, como a menudo se continúa a leer los derechos positivos nacionales ${ }^{12}$.

La idea dominante en el jurista que opera al interior de cada uno de los ordenamientos es buscar "la sola verdad jurídica, la que tiene su fuente en la ley y que viene fielmente reconstruida por la doctrina y aplicada por la jurisprudencia" (Sacco); en otras palabras, el principio de unicidad de la regla del derecho genera en el jurista el convencimiento de que la regla legal, la regla doctrinal y la regla jurisprudencial tienen el mismo contenido y que son, por eso mismo, intercambiables. Donde fuese percibida una deformidad, esta sería imputable a un error del intérprete.

En la construcción de la ley, la doctrina contribuye a la dinámica de formación, pero hoy en día, en el mundo occidental, no produce directamente y con autoridad derecho. Sin embargo, no siempre fue así en el pasado, ni es así en todas partes hoy en día. Por lo tanto, se debe tener mucho cuidado en distinguir la formación activa o dinámica de los demás, y retirarse de la visión del positivismo legislativo - bardo de "unicidad de la regla" - a favor de una visión (incluso positivista) del derecho que asigna a cada uno su propio papel, de acuerdo a los tiempos y lugares.

La doctrina, una vez más, que puede influenciar a los que toman decisiones imperativas. El problema es: ¿cuánto y cómo afectan las decisiones de las personas del poder político y, por lo que aquí interesa, las de los jueces en general, y de los jueces constitucionales en particular?

Hay ordenamientos en los que los tribunales normalmente se fortalecen con sus propios argumentos con referencia expresa a monografías, artículos, ensayos de diversa índole, artículos de enciclopedia, e incluso de tesis doctorales (este es el caso, por citar algunos ejemplos, de Canadá y Suiza); y hay sistemas en los que se considera, si no es un sacrilegio, por lo menos inútil para los fines del juez: por ejemplo, la ausencia de referencias doctrinales en la jurisprudencia de la Corte Constitucional italiana por el influjo de

\footnotetext{
12 "La disociación entre los formantes", por lo tanto, se refiere al fenómeno por el cual las normas jurídicas, los principios y la aplicación de la jurisprudencia, las opiniones doctrinales no convergen hacia el mismo resultado.
} 
específicas disposiciones de leyes ${ }^{13} \mathrm{o}$ de la praxis que prohíbe citar la doctrina jurídica en las sentencias, disposiciones que condicionan a los jueces -inclusive los constitucionales, a causa del continuum entre la jurisdicción ordinaria y la jurisdicción constitucional-en la búsqueda de los materiales seleccionados para la solución de un caso (Francia y España). La prohibición aleja al juez, una vez inmerso en la profesión, de los estudios teóricos realizados en la universidad, los cuales prestan bastante atención a la doctrina, y lo induce a buscar dentro de la casuística el precedente útil.

Además del estilo tradicional de las sentencias, vale destacar la apertura no solo a la doctrina interna sino también a la extranjera -que se atribuye a fenómenos tanto objetivos (globalización de la ley) como subjetivos - manifiesta en la selección de los jueces como un personal que ahora viaja más y hace estancias en el extranjero en prestigiosas universidades, de donde regresa conociendo otras pautas legales y actitudes de importancia cultural.

En las diversas facultades de derecho en el mundo en el que se forman los jueces a menudo existe la afirmación de la doctrina diferente. La cultura jurídica del juez, en otras palabras, puede variar de acuerdo al lugar en que se encuentra principalmente su formación, y también, en el caso del derecho comparado, en la que tenga estudios y especializaciones fructíferos ${ }^{14}$.

Por último, es importante señalar que el tribunal constitucional colombiano es uno de los más prestigiosos de América Latina y del mundo. Si bien, en principio Colombia se encuentra en el Sistema Judicial Latinoamericano que no se guía por los mismos principios que el anglosajón o "common law", también es cierto, que este tribunal ha revolucionado y transformado la cultura jurídica, a partir de la interpretación progresiva y novedosa de la Constitución que permite pensar en la hibridez o cruce de las dos culturas (anglosajona y románica), lo que resulta ya incompatible con un régimen jurisprudencial estático. En todo caso, se trata de un tema de alta polémica académica y jurídica, que es muy importante para el objeto de la presente investigación que aborda y explica, entre

13 En Italia, se trata del artículo 118 de las disposiciones de actuación del Código Procesal Civil. Sobre su origen ver Gorla (1999).

14 L. Pegoraro, Derecho nacional, derecho internacional, derecho europeo: la circulación horizontal $y$ vertical entre formantes, Actas del V Congreso Nacional de Derecho Constitucional, México (2013). 
otros aspectos, el considerable número de obras y de doctrina que utiliza la Corte Constitucional colombiana en sus sentencias y que proviene de Estados de cultura anglosajona.

Todo lo anterior pone de manifiesto la importancia de un estudio sistemático sobre la relación entre la doctrina y la jurisprudencia en el mundo, y de manera especial, conforme el objeto del presente proyecto de investigación, en Colombia. Si bien, tal como se mostrará a continuación, la Corte Constitucional colombiana ha sido objeto de varias investigaciones y estudios académicos, también es cierto que faltan muchos temas por desarrollar e incluso investigaciones de corte sociológico, como se plantea en la presente investigación.

\section{LA CORTE CONSTITUCIONAL COLOMBIANA. PROLIFERACIÓN DE ESTUDIOS SOBRE SU ACTUAR JURISDICCIONAL}

En este acápite y, como antecedente, se resalta el seguimiento realizado por la Corporación Excelencia en la Justicia a las altas cortes colombianas, y la correspondiente socialización de datos y estadísticas sobre el sector justicia, de manera especial, y para efectos de la presente investigación, sobre la procedencia, género, escolaridad y nivel de estudio de los magistrados de la Corte Constitucional colombiana. Por ejemplo, en materia de caracterización de género y desde una perspectiva comparada con las otras altas cortes colombianas, se observa que la Corte Constitucional ha tenido mayor participación de hombres que de mujeres, en un porcentaje de 89 a 11\%, respectivamente. Las cifras de mayor participación de los hombres se reiteran con un leve margen de diferencia, para el Caso del Consejo de Estado (69\% hombres y 31\% mujeres) y Corte Suprema de Justicia (77\% hombres y 23\% mujeres). "Si bien, Colombia se encuentra dentro de los paises latinoamericanos con mayor representación del género femenino en el sistema judicial, las cifras recolectadas por la CEJ muestran que el porcentaje de participación en cada una de las cortes no alcanza a la tercera parte pues en promedio las mujeres de la Corte Suprema de Justicia, el Consejo de Estado y la Corte Constitucional solo representan el 22\%"15.

15 D. Sanclemente \& X. Poveda, "Descubra quiénes componen las Altas Cortes en Colombia". La República (7 de octubre de 2013). Disponible en: http://www.urosario.edu.co/urosario_files/ 
Igualmente, el estudio arroja cifras sobre las universidades de procedencia, a corte del año 2009, según la CEJ, el 44\% de los magistrados provienen de las universidades del Rosario y Javeriana. Estos datos se cruzarán con todas las variables y preguntas que arroja el proyecto de investigación sobre circulación de la doctrina en la jurisprudencia del alto tribunal constitucional colombiano.

Los datos también arrojan información sobre los estudios de posgrado de los magistrados de la Corte Constitucional, los cuales en un $100 \%$ tienen estudios de posgrados, con algunos integrantes que ostentan nivel de maestría y doctorado. Así mismo, y frente al tema del sector de procedencia, se resalta que los magistrados de la Corte Constitucional, provienen en un 56\% del sector público. Tal como se ha señalado, estos datos constituyen un insumo para la investigación y un reto de actualización, ya que la información está a corte del año 2009.

También existen estudios orgánicos de la Corte Constitucional, como la creación de la Asamblea Constituyente de 1991, su rol institucional y su definición como titular de la jurisdicción constitucional, su composición (número de magistrados y sus requisitos para serlo) y sus periodos de elección ${ }^{16}{ }^{17}$. Por otro lado, desde el punto de vista funcional, se ha escrito sobre la Corte Constitucional como un juez que se dirige a un auditorio universal ${ }^{18}$; la tipología de las sentencias constitucionales colombianas ${ }^{19}$; el control de constitucionalidad $^{2021}$; la clasificación del control constitucional en Colombia ${ }^{22}$; el inhibicionismo constitucional ${ }^{23} 24$; la función hermenéutica de la

f6/f6868318-7a7a-4320-bfe5-7706fc5c10c7.jpg

16 L. C. Sáchica, La Corte Constitucional y su jurisdicción, Temis, Bogotá (1993).

17 C. M. Molina, El rol institucional de la Corte Constitucional 28 Revista de Derecho, Universidad del Norte, 213-242 (2007).

18 P. A. García, J. O. Agurrie. \& M. Albarracín, ¿A quién le habla la Corte Constitucional colombiana? El juez y el auditorio universal. 39 Revista Facultad de derecho y ciencias políticas, No. 110, 77-95 (2009).

19 H. A. Olano, Tipología de nuestras sentencias constitucionales, Vniversitas Jurídica, Pontificia Universidad Javeriana (2004).

20 L. R. Gómez, El control constitucional en Colombia sobre el inhibicionismo de la Corte Constitucional en los 100 años del control de la acción pública, 122 Vniversitas Jurídica, 169-212 (2011).

21 J. Tobo, La Corte Constitucional y el control de constitucionalidad en Colombia, Ediciones Jurídicas Gustavo Ibáñez, Bogotá (2004).

22 M. F. Quinche, Derecho Constitucional Colombiano de la Carta de 1991 y sus reformas, 3a ed., Editorial Universidad del Rosario, Bogotá (2009).

23 L. C. Sáchica, óp. cit.

24 L. R. Gómez, óp. cit. 
Corte, el precedente constitucional y su estructura argumentativa ${ }^{25}$; la acción pública de inconstitucionalidad ${ }^{26}$; las sentencias con efectos reparativo ${ }^{27}$; la modulación de sentencias y efectos de los fallos de control de constitucionalidad ${ }^{28} 29$; la cosa juzgada constitucional, el juicio integrado de constitucionalidad ${ }^{30}$; las vías de hecho y la acción de tutela contra providencias ${ }^{31}$; la interpretación constitucional, obligatoriedad del precedente judicial y análisis de líneas jurisprudenciales ${ }^{32}$; el uso del precedente extranjero por parte de la Corte Constitucional colombiana ${ }^{33}$; entre otros.

Además de lo anterior, un gran número de publicaciones ha girado en torno al estudio de su jurisprudencia, en específico a las temáticas desarrolladas en sus sentencias. La mayoría de textos estudian la jurisprudencia de la Corte Constitucional en materia de derechos fundamentales ${ }^{34}$, lo que se relaciona directamente con la parte dogmática de la Constitución, en donde se incluyen temas como la procedencia de la acción de tutela ${ }^{35}$; los derechos a la vida, a la integridad física, a la dignidad, a la igualdad, al reconocimiento de la personería jurídica, a la intimidad, al buen nombre, a la honra, al libre desarrollo de la personalidad, a la libertad de conciencia, al

25 J. C. Lancheros, El precedente constitucional en Colombia y su estructura argumentativa. Síntesis de las experiencias de un sistema mixto de constitucionalidad a la luz de la Sentencia T-292 de 2006 de la Corte Constitucional, 1 Díkaion, No. 21, Universidad de la Sabana, 159-186 (2012).

26 D. Mendieta, La acción pública de inconstitucionalidad: a propósito de los 100 años de su vigencia en Colombia, 120 Vniversitas, 61-84 (2010).

27 J. P. Sarmiento, Sentencias de la Corte Constitucional con efectos reparativos, entre el Juez Administrativo y el Juez Constitucional, 121 Vniversitas, 161-192 (2010).

28 J. P. Sarmiento, La modulación de sentencias como medio para articular la oportunidad política de la Corte Constitucional Colombiana. El caso de las parejas del mismo sexo, 37 Revista de Derecho Universidad del Norte (2012).

29 M. F. Quinche, Derecho Constitucional Colombiano de la Carta de 1991 y sus reformas, $3^{\mathrm{a}}$ ed., Editorial Universidad del Rosario. Bogotá (2009).

30 S. Insignares \& V. Molinares, La dignidad humana: incorporación de la jurisprudencia del Tribunal Europeo de Derechos Humanos por la Corte Constitucional Colombiana, 36 Revista de Derecho (2011).

31 M. F. Quinche, Vias de hecho. Acción de tutela contra providencias, Editorial Universidad del Rosario, Bogotá (2007).

32 D. E. López, El derecho de los jueces: obligatoriedad del precedente constitucional, análisis de sentencias y líneas jurisprudenciales y teoría del derecho judicial, 2a ed., Legis, Bogotá (2006).

33 L. M. Escobar, El uso del precedente extranjero por parte de la Corte Constitucional colombiana, 13 International Law Revista Colombiana de Derecho Internacional, 391-409 (2008).

34 R. Uprimny, La dialéctica de los Derechos Humanos en Colombia, Fundación Universitaria Autónoma de Colombia, Bogotá (1992).

35 M. Monroy \& F. Álvarez, Jurisprudencia de la Corte Constitucional sobre la acción de tutela, Tomo I, Biblioteca Jurídica Diké (1993). 
debido proceso, a la salud y a la vivienda digna ${ }^{36}{ }^{37}$; o el desarrollo jurisprudencial de la Corte sobre tutela contra tutela y el Estado de cosas inconstitucional en el desplazamiento forzado y su incidencia en el derecho fundamental de la infancia y la adolescencia a tener una familia en Colombia ${ }^{38}$. Por otra parte, se ha escrito sobre la recepción de la jurisprudencia internacional sobre derechos humanos por parte de la Corte ${ }^{39}{ }^{40}$, y en particular acerca de la incorporación de la jurisprudencia del Tribunal Europeo de Derechos Humanos relacionada con el derecho a la dignidad humana ${ }^{41}$. Igualmente, se encuentra una lectura de la jurisprudencia constitucional desde el punto de vista orgánico, en temas como: mecanismos de reforma constitucional, el referendo y el plebiscito, el sistema electoral, la participación ciudadana ${ }^{42}$ y los partidos políticos ${ }^{43}$, la Constitución colombiana y los estados de excepción ${ }^{44}$, organización territorial y la justicia constitucional colombiana ${ }^{45}$.

Otras publicaciones, en cambio, han estudiado la tendencia de la jurisprudencia de la Corte Constitucional en materia de derechos económicos, sociales y culturales ${ }^{46}$. En cuanto a temas de actualidad, se pueden destacar escritos sobre la influencia de

36 E. Leiva, La corrección moderada de los padres y el derecho al libre desarrollo de la personalidad de sus hijos a la luz de la jurisprudencia constitucional, 46 Revista de Derecho Privado (2011).

37 A. L. Vélez. Salud y enfermedad: la contribución de la Corte Constitucional de Colombia, 17 Hacia la promoción de la salud, No. 2, 91-109 (2012).

38 Yadira Alarcón P. \& Luis Miguel Hoyos, El Estado de cosas inconstitucional en el desplazamiento forzado y su incidencia en el derecho fundamental de la infancia y la adolescencia a tener una familia en Colombia, en La Constitución 20 años después. Visiones desde la teoría y la práctica constitucional, Pontificia Universidad Javeriana, Bogotá (2011).

39 C. M. Ayala, Recepción de la jurisprudencia internacional sobre Derechos Humanos por la Jurisprudencia Constitucional, en Corte Constitucional y Consejo de Estado, Jurisdicción Constitucional de Colombia. La Corte Constitucional 1992-2000: realidades y perspectivas, Imprenta Nacional, Bogotá (2001).

40 D. Olarte \& J. González, La influencia de los pronunciamientos de organismos internacionales en la jurisprudencia de la Corte Constitucional colombiana, 12 Materia de Derechos Económicos, Sociales y Culturales DESC. International Law Revista Colombiana de Derecho Internacional, 253-300 (2008).

41 S. Insignares \& V. Molinares, óp. cit.

42 C. A. Coronel, La participación ciudadana en el derecho electoral colombiano, Doctrina y Ley, Bogotá (2005).

43 M. F. Quinche, reforma política y referendo en Colombia. Dentro de los procesos de la reforma de la constitución de 1991, Centro Editorial Universidad del Rosario, Bogotá (2004).

44 P. P. Vanegas, La Constitución colombiana y los estados de excepción: veinte años después, 27 Revista Derecho del Estado, 261-290 (2011).

45 L. Estupiñán, Desequilibrios territoriales. Estudio sobre la descentralización y el ordenamiento territorial colombiano. Una mirada desde el nivel intermedio de gobierno (2012).

46 A. M. Gutiérrez, Tendencia actual de amparo en materia de derechos económicos, sociales y culturales en la jurisprudencia de la Corte Constitucional, Revista Derecho del Estado (2010). 
la Corte Constitucional en la economía ${ }^{47}$, la constitucionalización del derecho privado ${ }^{48} \mathrm{y}$ el análisis de su jurisprudencia atinente a movimientos sociales de mujeres y pueblos indígenas ${ }^{49}$, derechos de las parejas del mismo sexo ${ }^{50}$, la afectación de las redes sociales a los derechos fundamentales ${ }^{51} \mathrm{y}$ los casos de matoneo o bullying ${ }^{52}$.

Como se observa, no existe ningún estudio que de manera puntual aborde el tema de la circulación del formante doctrinal en las sentencias del tribunal constitucional, lo que realmente justifica el desarrollo de la presente investigación y la creación del sistema de información que a continuación se explica, herramienta fundamental para el desarrollo metodológico y la resolución del problema de investigación planteado.

\section{UN SISTEMA DE INFORMACIÓN WEB PARA EL ESTUDIO DE LA CIRCULACIÓN DE LA DOCTRINA EN LAS SENTENCIAS DE LA CORTE CONSTITUCIONAL ${ }^{53}$}

En los últimos años las recopilaciones jurídicas han sido patrocinadas esencialmente por entidades públicas oficiales en lo que se definen, desde una perspectiva de documentación, como bases de

47 H. Torres, La Corte Constitucional: entre la economía y el derecho, Universidad del Quindío, Armenia (2002).

48 J. J. Calderón, La constitucionalización del derecho privado. La verdadera historia del impacto constitucional en Colombia, Temis, Bogotá (2011).

49 G. A. Durango, Los movimientos sociales desde la perspectiva de las mujeres y pueblos indígenas. Un análisis desde la jurisprudencia de la Corte Constitucional colombiana, 37 Revista de derecho (2012).

50 M. Londoño, Derechos de las parejas del mismo sexo Un estudio desde la jurisprudencia de la Corte Constitucional Colombiana, 11 Opinión Jurídica, No. 22, 45-64 (2012).

51 D. Sanclemente \& A Hinestrosa, Novedades: trascendencia de las redes sociales en el ordenamiento jurídico colombiano y la afectación de los derechos fundamentales Sentencia T-260 del 29 de marzo de 2012, Corte Constitucional de Colombia, 9, 305-311 (2012).

52 J. E. Roa, La libertad de expresión en las redes sociales y los casos de "school bullying". La pérdida y el coste de oportunidad en la Sentencia T-713 de 2010, 26 Revista Derecho del Estado, 209-213 (2011).

53 El semillero de investigación de la Línea de Territorio, Descentralización y Democracia, adscrita al grupo de Derecho Público de la Facultad de Jurisprudencia de la Universidad del Rosario, fue fundamental para el montaje, seguimiento y acopio de la información, a continuación el nombre de los monitores, coordinadores y líderes de los estudiantes (finales 2012 y todo el año 2013): María Isabel Eslava Castillo, Sergio Peláez Hidalgo, Juliana Castro Gutiérrez, Simón David Rodríguez Rojas, Daniela Calderón Vélez y María Paula Romero Piñeres. 
datos jurídicas ${ }^{54}{ }^{55}$. Estas bases de datos jurídicas han incluido en sus procesos las tecnologías de la información y las comunicaciones, con lo que permiten indexar información y facilitan su acceso y consulta por parte de la sociedad, contribuyendo a la construcción de datos fiables que permiten teorizar y realizar estudios sistémicos.

Las grandes bases de datos jurídicas surgieron ya desde los años setenta en los Estados Unidos de Norteamérica, y se propagaron posteriormente a Europa ${ }^{56}$ en donde la Recomendación 95 del 2011 del Comité de Ministros del Consejo Europeo (Council of Europe (Committee of Ministers), 1995) establece los objetivos básicos de un sistema de consulta de jurisprudencia, entre los cuales está: "Facilitar la investigación sobre jurisprudencia" y "Proporcionar información con propósitos estadísticos".

En nuestros días, las bases de datos jurídicas han evolucionado al concepto de la "informática jurídica documentaria", "informática jurídica de control y gestión" e "informática jurídica metadocumentaria" $" 57$.

Para el caso de la Administración Española, el Reglamento del Centro de Documentación Judicial (Cendoj) ${ }^{58}$ (Consejo General del Poder Judicial) especifica un poco más los objetivos de la Recomendación 95 del 2011, colocando como uno de sus objetivos "Realizar estudios de naturaleza estadística, económica y sociológica sobre la actividad judicial, recabando información de los órganos judiciales y promoviendo la suscripción de convenios relativos a las actividades y estudios del Cendoj con otros servicios y centros de documentación que persigan análoga finalidad, así como con otras instituciones"; y "Gestionar, con la colaboración que se precise, la instalación y

54 “Conjuntos de documentos jurídicos básicos (legislación, jurisprudencia, interpelaciones parlamentarias y doctrina), almacenados en soportes magnéticos o de cualquier otro material y susceptibles de ser tratados, recuperados y transmitidos de forma total o parcial mediante procedimientos y medios informáticos, que con la aplicación de técnicas derivadas de la utilización de la informática jurídica pretenden ser utilizados con una finalidad divulgadora publica y generalizada de su contenido".

55 J. Páez Mañá, Bases de datos jurídicas: características, contenido, desarrollo y marco legal, Cindoc, Madrid (1994). J. Páez Mañá, Comentarios sobre algunas particularidades de las bases de datos jurídicas, Actualidad informática Aranzadi (1995).

56 Bing, Legal text retrieval and information services, Encyclopedia of Library and Information Science, New York (1991).

57 J. Téllez, Derecho Informático, $4^{\mathrm{a}}$ ed., Mc Graw Hill (2008).

58 Órgano técnico del Consejo General del Poder Judicial cuyas funciones son la selección, ordenación, tratamiento, difusión y publicación de información jurídica legislativa, jurisprudencial y doctrinal. 
actualización de las bibliotecas judiciales, sistematizar su régimen y funcionamiento y asegurar su conservación".

En Italia, por otro lado, el Instituto de la Documentación Jurídica del Consejo Nacional Italiano de Investigación desarrolló un proyecto de repositorio ${ }^{59}$ desde el Derecho de Capua de 960 a. C. hasta nuestros días, que tuvo como resultado el Vocabolario della lingua italiana (Vocabulario de la Lengua Italiana) con casi un millón de palabras jurídicas.

A nivel de iniciativas de investigación, el Departamento de Informática de la Universidad do Minho construyó una base de datos de ontologías en $\mathrm{XML}^{60}$ para compartir y re-usar el conocimiento, y detectar similitudes entre los documentos en una base de datos relacional ${ }^{61}$. En Ucrania se analizó la entropía y conocimiento legal de sus sistemas de información puestos en marcha desde $1996^{62}$ y en Noruega los investigadores presentan la importancia de la gestión del conocimiento en las firmas de abogados de ese país ${ }^{63}$.

En Colombia el Consejo Superior de la Judicatura diseñó y desarrolló el Sistema de Información de la Rama Judicial Colombia ordenado por la Ley Estatutaria de la Administración de Justicia (Ley 270 de 1996 ${ }^{64}$ ). Esta ley además estableció que todos los organismos que hacen parte de la rama, tienen el deber de suministrar la información necesaria para mantener actualizados los datos incorporados al sistema.

Lo anterior permitió crear el Centro de Documentación SocioJurídica de la Rama Judicial (Cendoj) (Sala Administrativa del Consejo Superior de la Judicatura, 2012) (Acuerdo No. 560 de 1999), que tiene como finalidad "permitir el acceso de los servidores judiciales y de la comunidad nacional e internacional, a la consulta,

59 A. Cammelli \& F. Socci, An Information System for a Historical Analysis of the ltalian Legal Lexicon, en Dexa'97 Proceedings of the 8th International Workshop on Database and Expert Systems Applications, Washington, DC, USA (1997).

60 Siglas en inglés de XXtensible Markup Language, "lenguaje de marcas extensible".

61 M. Costa \& J. Neves, Practical knowledge management in the legal domain, en Fourth IntmrJJtiorull Conforence on lawwledge-Based lntelligent Engineering Systems y Allied Technologies, Brighton, UK (2000).

62 L. Nykolaychuk \& O Chehodar, Problems in Creation of Information Systems of Legal Knowledgeand Estimation of Entropy of Legal Information, en 5th International Conference on "Modern Problems of Radio Engineering, Telecommunications and Computer Science” (TCSET), 2006, Lviv-Slavsko, Ukraine (2006).

63 P. Gottschalk, Knowledge Management in the Professions: The Case of IT Support in Law Firms, en 33rd Hawaii International Conference on System Sciences, Hawaii (2000).

64 En su artículo 106 (modificado por el Artículo 19 de la Ley 1285 de 2009). 
y el intercambio de información, documentación y bibliografía sociojurídica y de derecho comparado". Este centro de documentación socio-jurídica también está encargado de la administración del Sistema de Información Doctrinario y Normativo (SIDN) (Sala Administrativa del Consejo Superior de la Judicatura, 2003), que permite a los usuarios realizar consultas de información doctrinaria y normativa a través de diferentes criterios de búsqueda. Además del sidn, existe el Saidoj, creado por el Consejo Superior de la Judicatura mediante el Acuerdo 2371 de 2004, que adscribió el archivo de la extinta Justicia Regional al Cendoj, garantizando el derecho a la información y reprografía de la documentación de los antiguos juzgados regionales, vigentes entre el $1^{\circ}$ de julio de 1992 y el 30 de junio de 1999 (Sala Administrativa del Consejo Superior de la Judicatura, 2013).

Todo lo anterior se encuentra en consonancia con el Plan Nacional Tic 2010-2014 Eje Justicia (Ministerio de Tecnologías de la Información y las Comunicaciones, 2010), impulsado por el Ministerio de las Tecnologías de la Información y las Comunicaciones y la Corporación Excelencia en la Justicia (CEJ), el cual se centra principalmente en el Expediente Digital (ED), definiendo para las distintas cortes solo sistemas de información y repositorios para realizar búsquedas al servicio de los procesos propios de la rama judicial, tal como lo establece el Plan Estratégico de Tecnología de la Rama Judicial (PET) (Sala Administrativa del Consejo Superior de la Judicatura, 2012) aprobado por la Sala Administrativa del Consejo Superior de la Judicatura en uno de sus ejes estratégicos, la "gestión de la información" (Sala Administrativa del Consejo Superior de la Judicatura, 2012), que desde una perspectiva técnica contemplan proyectos como la mejora de accesibilidad, la integración de bases de datos e incorporación de Web 2.0.

Para el caso que nos compete en esta investigación, es relevante mencionar la relatoría de la Corte Constitucional, la cual "es una dependencia que tiene como función principal suministrar la información sobre las providencias que profiere la Corporación" (Corte Constitucional Colombiana, 2013), que facilita la consulta por medio de una página web, y cuya búsqueda puede realizarse a través de un índice temático desde el año 1992 a la fecha, por texto completo dentro de la sentencia o por un índice de normas desde el año 1992 hasta 
hoy en día. Incluso, se pueden buscar las providencias ingresando el número de la sentencia o el autor.

De lo presentando anteriormente se puede inferir que la consulta de jurisprudencia podría potenciarse con las capacidades técnicas que la tecnología informática posee en la actualidad. Lo que se propone en este trabajo es aportar importantes mejoras de coherencia, complejidad y transparencia en el análisis de la circulación de la doctrina de la jurisprudencia de la Corte Constitucional en referencias bibliográficas, es decir aplicar una "informática jurídica metadocumentaria" ${ }^{95}$ desde una perspectiva de la informática jurídica de investigación analítica, descubriendo y aplicando instrumentos matemáticos a lo que hasta ahora han sido investigaciones de interpretaciones principalmente semánticas pero que no analizan la fuente de la generación del contenido jurídico.

Este aporte en el ámbito de las tecnologías de la información y las comunicaciones se da con el diseño y puesta en marcha de un sistema de información web basado en tecnología de punta y de desarrollo propio y registrado por la Universidad Piloto de Colombia y la Universidad del Rosario, que permite realizar minería de datos $^{66}$ e inteligencia de negocio (George, 2006) a la "circulación" de la doctrina a través de las citas de la ciencia jurídica que se realizan en las sentencias de la Corte Constitucional Colombiana.

El sistema de información desarrollado en el marco de la investigación presentada permite resolver preguntas tales como: ¿Cuáles son los autores más citados y con qué editoriales publican? ¿Cuáles son los países y universidades que más influyen en la formación de nuestros magistrados y que abundan en las referencias de nuestra jurisprudencia? Es además una herramienta para conocer con mayor objetividad las escuelas jurídicas, filosóficas y académicas que circulan en la doctrina de la jurisprudencia de la Corte Constitucional colombiana; con ello se podría validar la premisa, generalizada en el mundo de la academia, según la cual no es suficiente producir "cultura" en sí, sino que es necesario probar que los resultados intelectuales "son consumidos" y que a su vez son productivos.

\footnotetext{
65 J. Téllez, Informática, instrumento del derecho informático, 3ª ed., Mc Graw Hill (2003). Recuperado en http://biblio.juridicas.unam.mx/libros/2/916/4.pdf

66 J. Han \& M. Kamber, Data Mining: Concepts and Techniques, Morgan Kaufmann (2000).
} 
El sistema de información web alberga datos relacionados con más de 19.000 sentencias proferidas por la Corte Constitucional colombiana desde el año 1992. Algunas de ellas carecen de citas doctrinales o documentales o incluso tienen una tendencia hacia la co-citación de sentencias hito producidas por la misma Corte Constitucional. Sin embargo, un número significativo de sentencias tiene citas tanto de documentos bibliográficos como hemerográficos, entre los cuales encontramos libros, capítulos, artículos, informes y documentos. Un análisis detallado de todos estos aspectos se presentará en próximas publicaciones del proyecto.

La aplicación diseñada e implementada fue desarrollada en HTML5, ASP.NET versión 4.5, AJAX y jQuery (jQuery Foundation; Microsoft, 2013a, 2013b) y utilizando una base de datos (ver definición 3.743, página 99 del Estándar IEEE24765-2010 ("Systems and software engineering -- Vocabulary," 2010)) relacional implementada en Microsoft SQL Server 2012 (Microsoft, 2013c).

El modelo de datos que se muestra en la Figura 1 permite organizar la información en grandes bloques o entidades tales como: magistrados, sentencias, libros, capítulos de libro, artículos, autores, co-citas y documentos. 


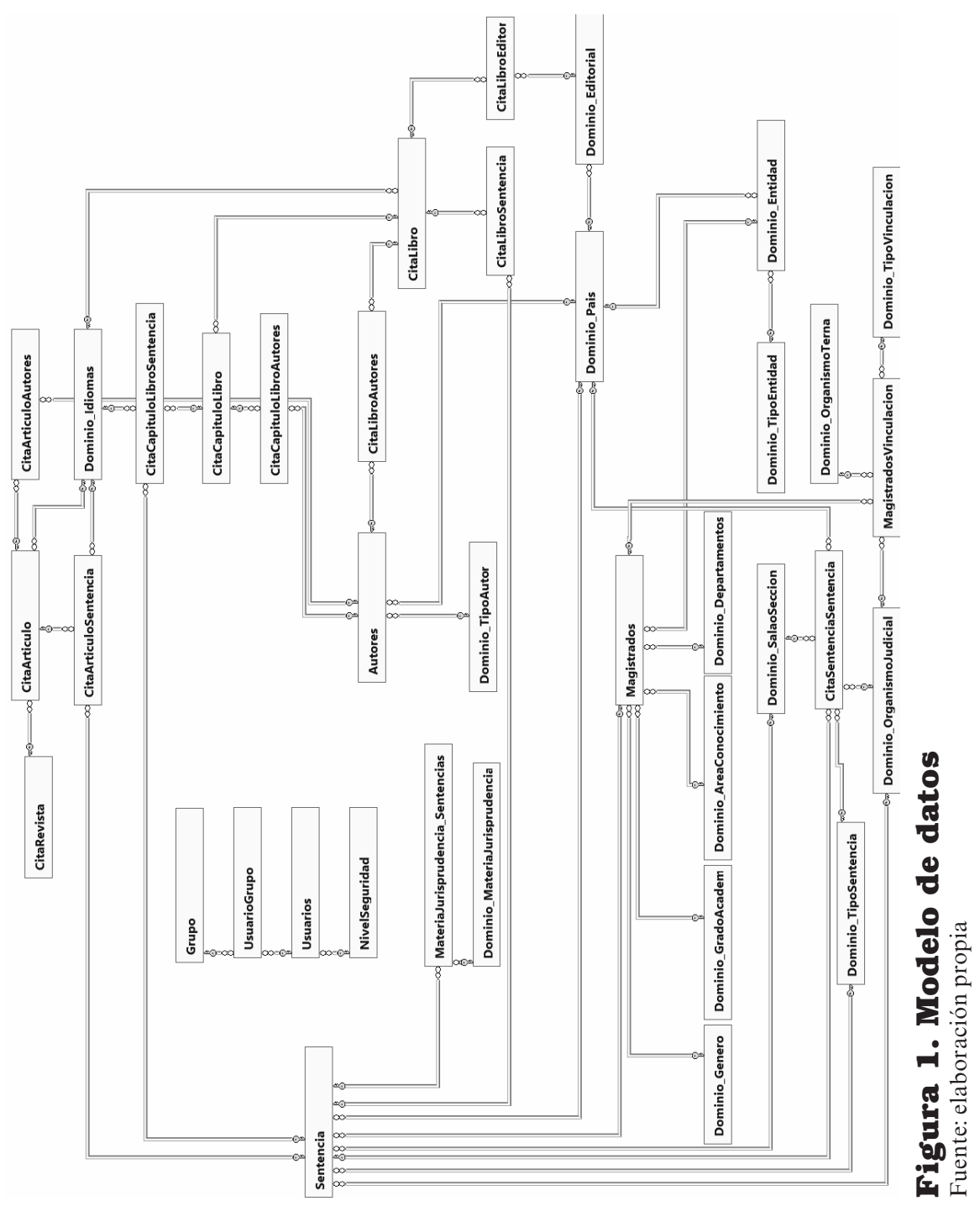

Esta estructura de datos permite analizar y abordar el problema a resolver en la investigación desde distintas perspectivas, con el fin de dar una respuesta cuantitativa, para su posterior análisis cualitativo, a las preguntas planteadas.

Por otro lado, la aplicación web ofrece de manera natural un entorno para los usuarios externos y visitantes y otro para los autenticados (analistas, auditores, directores y súper-administradores) con roles de usuarios definidos y funcionalidades diferenciadas, integrado un flujo de trabajo en su gestión. 
Al entrar en la aplicación se muestra una presentación del proyecto internacional y nacional, sus integrantes con el rol con el que participaron en el proyecto, un resumen de su perfil profesional y un enlace a utilizar para la herramienta (Ver Figura 2).

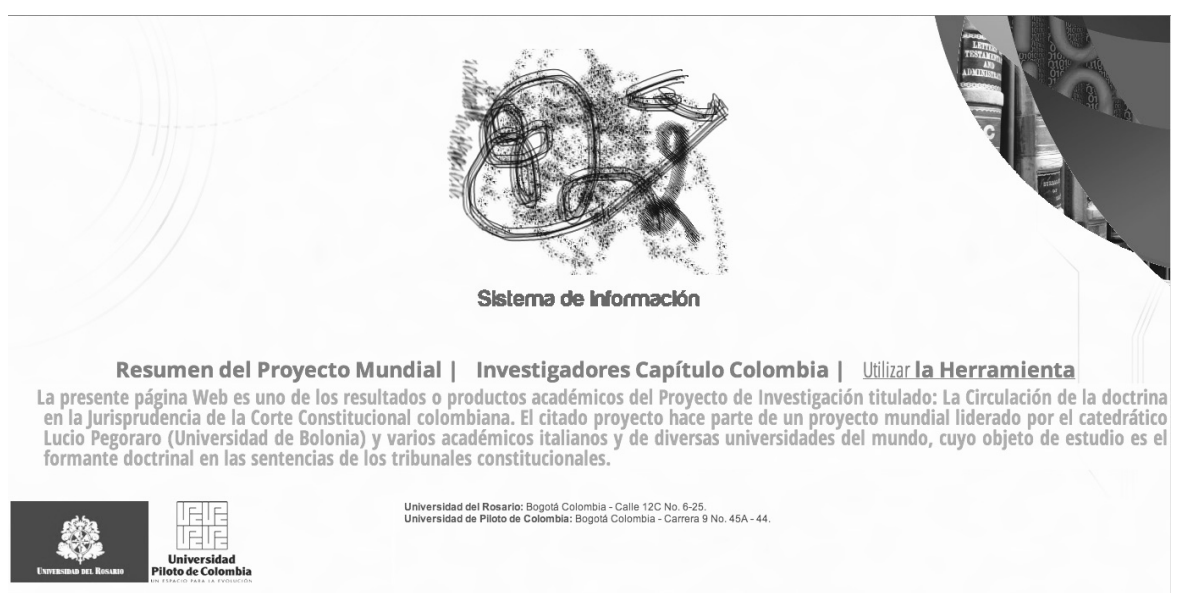

\section{Figura 2. Página de inicio}

Fuente: http://200.115.181.160/circulacionjurisprudencia/Default.aspx

Al entrar a la herramienta en modo visitante se puede tener acceso al "Análisis Cuantitativo", "Análisis Cualitativos" y "Datos Curiosos".

En el "Análisis Cuantitativo" se llaman "consultas SQ""67 implementadas en la base de datos para poder representarlos de forma gráfica; inicialmente este módulo muestra la batería de indicadores como fichas o tarjetas que permiten lanzar el módulo de indicadores. En la Figura 3 se muestra un ejemplo de estos indicadores para el análisis de algunos componentes de esta investigación.

67 Líneas de comando en lenguaje declarativo que permiten especificar operaciones lógicas, de álgebra, cálculo relacional o búsqueda de información con el fin de recuperar información de interés de bases de datos. 


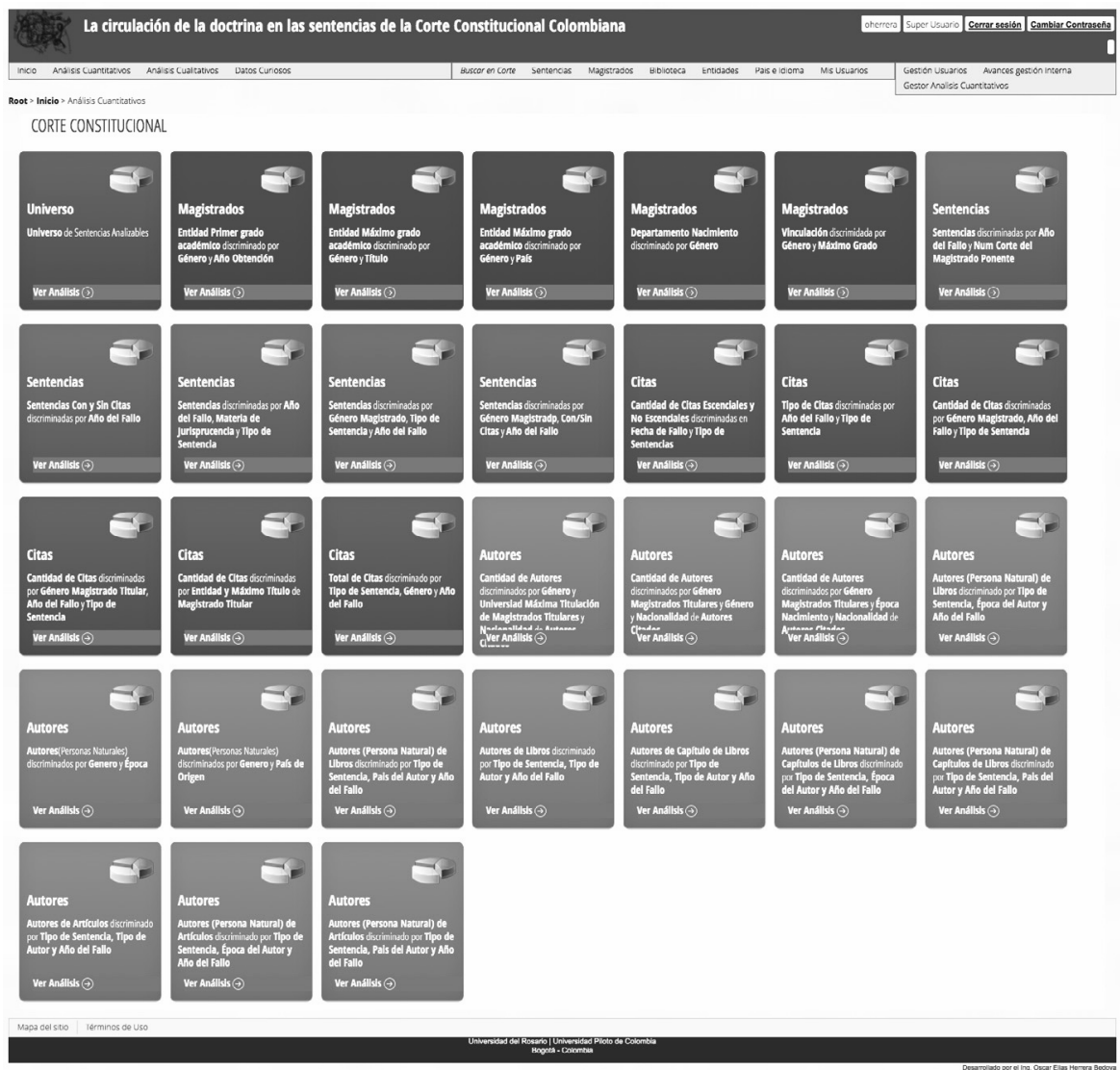

Figura 3. Módulo de fichas de indicadores

Fuente: http://200.115.181.160/circulacionjurisprudencia/Inicio.aspx

$\mathrm{Al}$ acceder a cualquiera de estas fichas tal como se muestra en la Figura 4 se aprecia: la descripción de la consulta, unos indicadores iniciales, tres tipos de gráficas dinámicas y relacionadas entre sí y una tabla de datos que muestra el total de la información de la consulta. A modo de ejemplo se muestran algunos resultados en las Figura 5 y Figura 6.

Los indicadores iniciales muestran el consolidado total de la consulta, así como el valor máximo, promedio y mínimo de la consulta solicitada. La gráfica de primer nivel (barra horizontal agrupada tipo stack) muestra un primer consolidado que se va discriminando con la gráfica de segundo nivel en torta y termina en un tercer nivel de detalle con una gráfica de barras no agrupadas. 


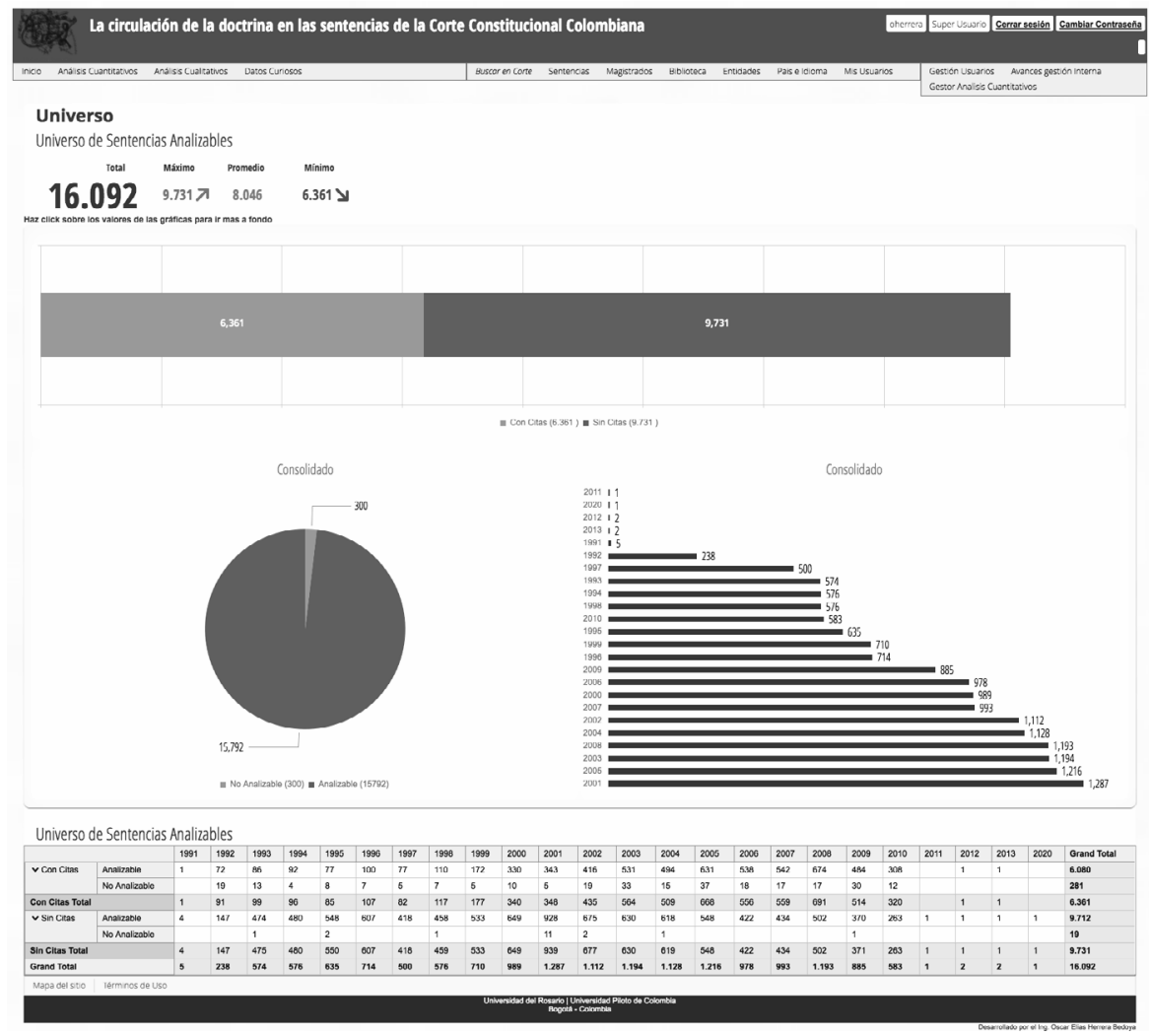

\section{Figura 4. Universo actual de sentencias bajo análisis}

Fuente: http://200.115.181.160/circulacionjurisprudencia/Graficas/PlantillaGrafica. aspx?Consulta $=$ Grafica_SentenciasAnalizables 


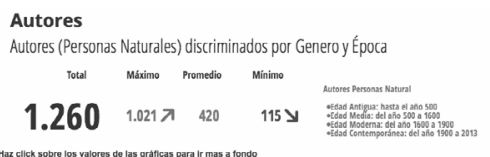

124

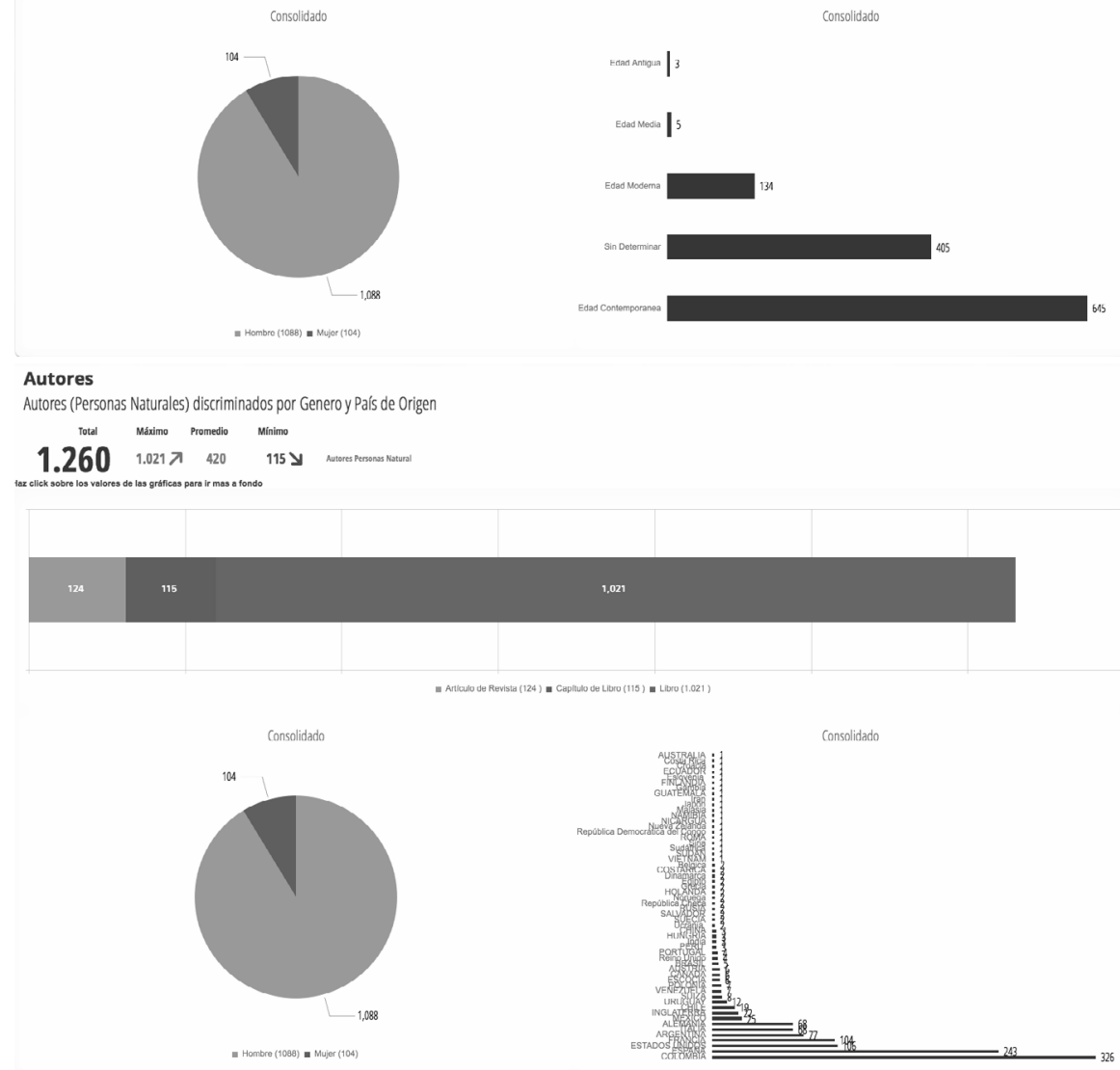

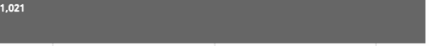

Consolidado

Figura 5. Autores citados por las sentencias bajo análisis (clasificadas por tipo de sentencia) discriminados por género, país de origen y época de nacimiento del autor

Fuente: http://200.115.181.160/circulacionjurisprudencia/Graficas/PlantillaGrafica. aspx?Consulta=Grafica_Autores_TipoObras_Genero_Epoca http://200.115.181.160/circulacionjurisprudencia/Graficas/PlantillaGrafica. aspx?Consulta=Grafica_Autores_TipoObras_Genero_Pais 

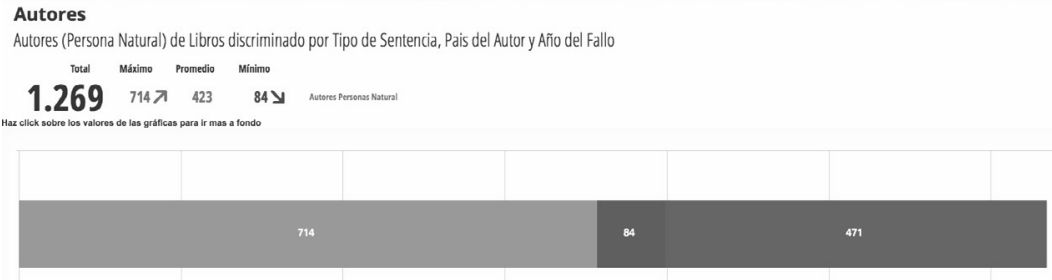

44

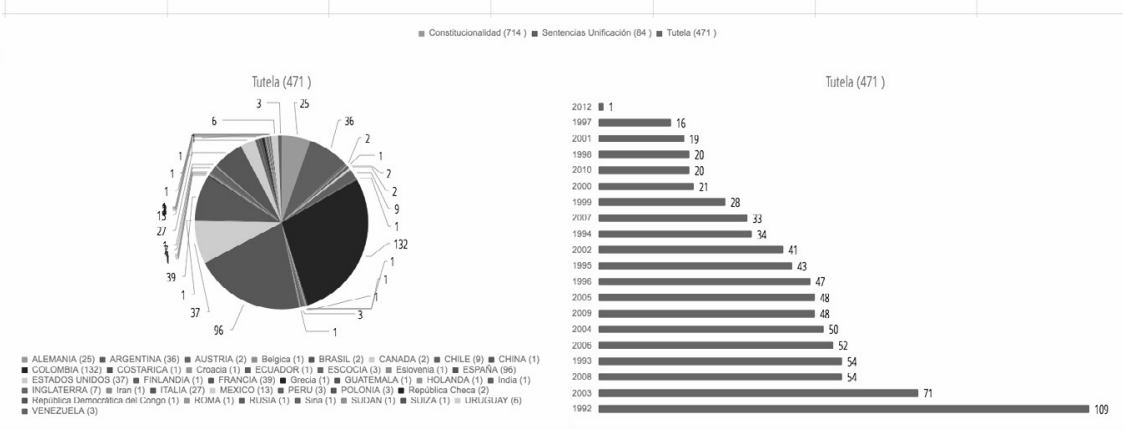

Figura 6. Autores (Personas natural) de Libros citados por las Sentencias bajo análisis (clasificadas por tipo de sentencia) discriminados por país del autor y año del fallo de la sentencia y filtrado por tipo de Sentencia Tutela

Fuente: http://200.115.181.160/circulacionjurisprudencia/Graficas/PlantillaGrafica. aspx?Consulta=Grafica_AutoresLibro_PaisAutor_TipoSentencia_Ano

Las consultas de los "análisis cuantitativo" y los "datos curiosos" se han dividido con relación a los principales entes de la investigación; en todos los casos se puede realizar un análisis cuantitativo cuidadoso relativo a cantidades, procedencia nacional o internacional o de nacimiento, frecuencia de aparición, género, si el análisis pertenece a citas esenciales o no, el país de origen y en definitiva todos aquellos campos que el sistema de información recopila, así como relacionar las obras citadas (libros, capítulos de libros, artículos de revista, co-citas, documentación pública), los autores de las citas, las editoriales, los magistrados y las sentencias.

En el backend, cuando inicia un usuario con rol analista, coordinador o administrador, este podrá gestionar sentencias, materia de jurisprudencia, tipo de sentencia, organismos judiciales, magistrados, grados académicos, materia de conocimiento de los máximos grados académicos, autores, tipo de autores, libros, capítulo 
de libros, artículos, revistas, editoriales, co-citas y documentos, entidades, idiomas y países.

A caso de ejemplo se muestra a continuación la gestión de sentencias (Ver Figura 7), si se ha ingresado en el sistema con el rol de analista solo podrá gestionar las sentencias que él hubiese creado, si se hace con el rol de coordinador podrá ver además de sus sentencias las sentencias de los analistas que estuviesen a su cargo y como súper-administrador es posible ver y gestionar la totalidad de las sentencias. En este apartado el usuario podrá filtrar, agrupar, ordenar y conocer la fecha y analista que realizó el último cambio.

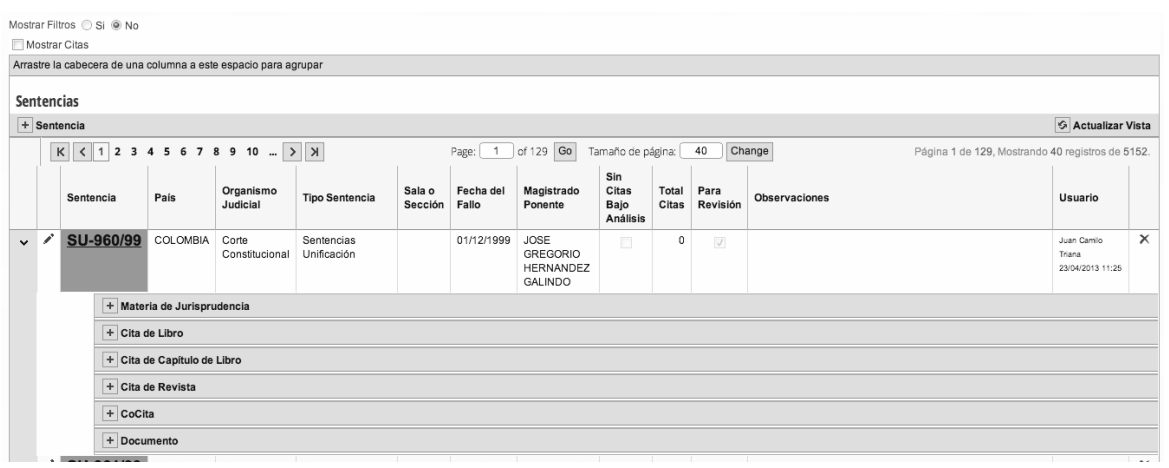

Figura 7. Módulo gestión de sentencias

Fuente: URL privada

Al editar o insertar información, la mayor parte de los campos se encuentran parametrizados, obligando al analista a seleccionar de listas con búsquedas inteligentes (buscar mientras se escribe) (Figura 8). En todo caso, siempre será posible agregar nuevos elementos a estas listas siguiendo un flujo de trabajo establecido con los coordinadores y la dirección del proyecto. 


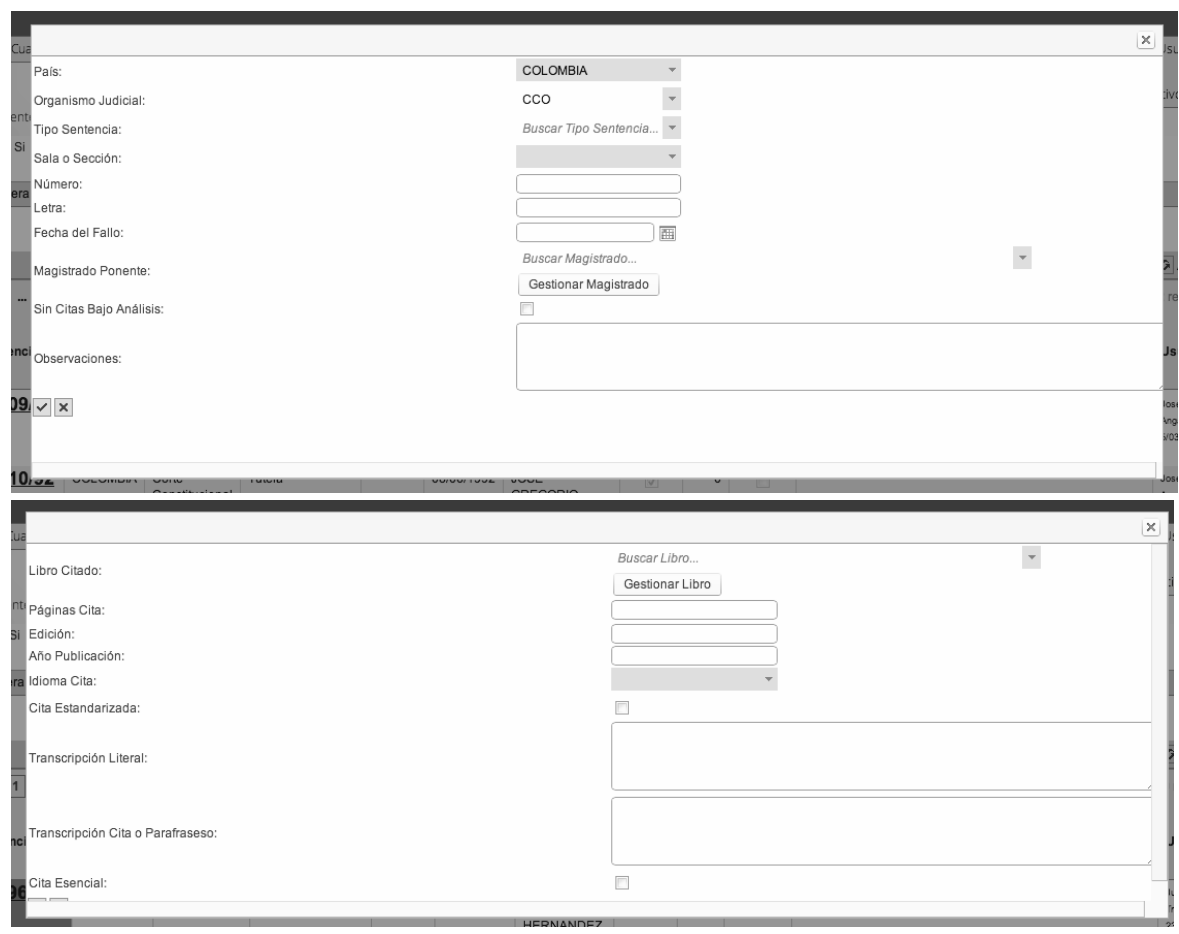

Figura 8 Ejemplo formulario de edición e inserción de datos

Fuente: URL privada.

En cuanto al módulo de biblioteca, en este apartado todos los usuarios autenticados podrán consultar la biblioteca de sentencias, autores, tipo autor, libros, capítulos de libros, artículos, revistas, editoriales, co-citas y documentos que se encuentren en la base de datos del sistema de información y que dependiendo del rol con el que inicien sesión podrán ser gestionados o solo ser consultados.

Este módulo también permitirá que los usuarios no autenticados puedan conocer las doctrinas citadas en formato interno de manejo bibliográfico de la Universidad del Rosario (similar a APA) así como consultar la biblioteca completa de la doctrina en la jurisprudencia colombiana.

A nivel de gestión también es posible conocer el directorio y roles de los usuarios que gestionan la aplicación, y la fecha y direcciones IP desde las que iniciaron sesión para interactuar con el sistema. 
De igual forma, cada registro posee un indicador de estado que permite conocer si la integridad de la información es correcta, a través de una batería de indicadores de gestión que ha permitido, en el proceso de carga de información por parte de los analistas, facilitar a los coordinadores la auditoría de calidad de los datos y demás procesos inherentes al desarrollo de una investigación de las características presentadas en este trabajo. 


\section{A MANERA DE CONCLUSIón}

Si bien existen diversos estudios y publicaciones sobre el papel y el desarrollo de la Corte Constitucional colombiana, no se encontró evidencia de estudios macro e investigaciones sobre la circulación del formante doctrinal, escuelas, tendencias, países importadores, universidades y editoriales que marquen la producción de sentencias de manera explícita o implícita, de la Corte Constitucional colombiana. Estado del arte que justifica la creación y desarrollo del presente proyecto de investigación.

Todo lo anterior corrobora la importancia, originalidad y novedad de este proyecto de investigación mundial y de su capítulo de investigación en Colombia y la creación del sistema de información introducido en este trabajo que contribuye de manera innovadora y determinante al mejoramiento de las actividades de investigación y análisis de la doctrina y aspectos subyacentes de la jurisprudencia colombiana. Tal como se establece Resnyansky ${ }^{68}$, el modelamiento social hoy en día debe pasar por el tamiz de la interdisciplinaridad con el fin de alimentar la toma de decisiones, el análisis social, y los componentes tecnológicos desde la perspectiva de múltiples disciplinas construyendo objetos de conocimientos sólidos y estructurados en el mayor número de dimensiones del saber.

También se pudo corroborar que las tecnologías de la información, metodología central de esta investigación, se encuentran hoy por hoy en uno de sus mejores momentos para aportar en los procesos investigativos de la informática jurídica metadocumentaria, y se podrá de forma progresiva incorporar nuevas funcionalidades y análisis de la doctrina en la jurisprudencia colombiana en el marco de la investigación internacional al que pertenece este trabajo.

68 L. Resnyansky, Social Modeling as an Interdisciplinary Research Practice. Computational Cultural Dynamics, 20-27 (2008). 


\section{REFERENCIAS}

\section{Libros}

A. Somma, L'uso giurisprudenziale della comparazione giuridica, Giuffrè, Milano (2004). , L'uso giurisprudenziale della comparazione nel diritto interno e comunitario, Giuffrè, Milano (2001).

A. Watson, Legal Transplants: An Approach to Comparative Law, Scottish Academic Press, Edimburgh (1974).

B. Markesinis \& J. Fedtke, Giudici e diritto straniero. La pratica del diritto comparato, Bolonia (2009).

Bing, Legal text retrieval and information services, Encyclopedia of Library and Information Science, New York (1991).

C. A. Coronel, La participación ciudadana en el derecho electoral colombiano, Doctrina y Ley, Bogotá (2005).

C. Decaro \& N. Lupo, II “dialogo” tra parlamenti: obiettivi e risultati, Roma (2009).

Cl. L'Heureux-Dubé, The Importance of Dialogue: Globalization and the International Impact of the Rehnquist Court, 15 y ss. (1998).

D. E. López, El derecho de los jueces: obligatoriedad del precedente constitucional, análisis de sentencias y líneas jurisprudenciales y teoría del derecho judicial, $2^{\mathrm{a}}$ ed., Legis, Bogotá (2006). Bogotá (2002).

D. Maus, Le recours aux précedents étrangers et le dialogue des cours constitutionnelles. (2009).

F. Melin-Soucramaniem, Le recours à 'l'argument de droit comparé' par le juge constitutionnel. Quelques problèmes théoriques et tecniques, Dalloz, Paris (2005).

F. Fernández, The Spanish Constitution in the European Constitutional Context - La Constitución Española en el Contexto Constitucional Europeo, Dykinson, Madrid (2003).

G. Gorla, I 'Grandi Tribunali’ italiani fra i secoli XVI e XIX: un capitolo incompiuto della storia politico-giuridica d'Italia (1999).

G. Canivet, M. Andenas \& D. Fairgrieve, Comparative Law Before the Courts, British Institute of International and Comparative Law, Londres (2004).

H. Torres, La Corte Constitucional: entre la economía y el derecho, Universidad del Quindío, Armenia (2002).

J. Hany \& M. Kamber, Data Mining: Concepts and Techniques, Morgan Kaufmann (2000).

J. J. Calderón, La constitucionalización del derecho privado. La verdadera historia del impacto constitucional en Colombia, Temis, Bogotá (2011). 
J. Páez Mañá, Bases de datos jurídicas: características, contenido, desarrollo y marco legal, Cindoc, Madrid (1994).

Comentarios sobre algunas particularidades de las bases de datos jurídicas, Actualidad informática Aranzadi (1995).

J. Téllez, Derecho informático, $4^{\mathrm{a}}$ ed., Mc Graw Hill (2008).

, Informática, instrumento del derecho informático, $3^{\mathrm{a}}$ ed., Mc Graw Hill (2003). Disponible en: http://biblio.juridicas.unam.mx/libros/2/916/4.pdf

J. Tobo, La Corte Constitucional y el control de constitucionalidad en Colombia, Ediciones Jurídicas Gustavo Ibáñez, Bogotá (2004).

L. C. Sáchica, La corte constitucional y su jurisdicción, Temis, Bogotá (1993).

L. Estupiñán, Desequilibrios Territoriales. Estudio sobre la descentralización y el ordenamiento territorial colombiano. Una mirada desde el nivel intermedio de gobierno (2012).

L. George, Making Business Intelligence More Useful. Disponible en: http://doi. ieeecomputersociety.org/10.1109/MC.2006.318 (2006).

L. Resnyansky, Social Modeling as an Interdisciplinary Research Practice. Computational Cultural Dynamics, 20-27 (2008).

M. Costa \& J. Neves, Practical knowledge management in the legal domain, en Fourth IntmrJJtiorull Conforence on lawwledge-Based Intelligent Engineering Systems y Allied Technologies, Brighton, UK (2000).

M. F. Quinche, Derecho Constitucional Colombiano de la Carta de 1991 y sus reformas, 3ra ed., Editorial Universidad del Rosario. Bogotá (2009).

, Reforma Politica y Referendo en Colombia. Dentro de los procesos de la reforma de la constitución de 1991, Centro Editorial Universidad del Rosario, Bogotá (2004).

, Vías de hecho. Acción de tutela contra providencias, Editorial Universidad del Rosario, Bogotá (2007).

M. Monroy y F. Álvarez, Jurisprudencia de la Corte Constitucional sobre la acción de tutela, Tomo I, Biblioteca Jurídica Diké (1993).

R. C. Van Caenegem, Judges, Legislators and Professors. Chapters in European Legal History, Cambridge University Press, Cambridge (1987).

R. Uprimny, La dialéctica de los derechos humanos en Colombia, Fundación Universitaria Autónoma de Colombia, Bogotá (1992).

T. Groppi \& M. Ponthoreau, The Use of Foreign Precedents by Constitutional Judges, Hart Publ., Oxford. (2013).

U. Drobnig \& S. Van Erp, The Use of Comparative Law by Courts, Actas del XIV Congrès international de droit comparé (1999). 


\section{Contribuciones en obras colectivas}

A. Cammelli \& F. Socci, An Information System for a Historical Analysis of the ltalian Legal Lexicon, en Dexa '97 Proceedings of the 8th International Workshop on Database and Expert Systems Applications, Washington, DC, USA (1997).

C. M. Ayala, Recepción de la jurisprudencia internacional sobre derechos humanos por la jurisprudencia Constitucional, en Corte Constitucional y Consejo de Estado, Jurisdicción Constitucional de Colombia. La Corte Constitucional 1992-2000: realidades y perspectivas, Imprenta Nacional, Bogotá (2001).

L. Nykolaychuk \& O Chehodar. Problems in Creation of Information Systems of Legal Knowledgeand Estimation of Entropy of Legal Information, en 5th International Conference on "Modern Problems of Radio Engineering, Telecommunications and Computer Science” (TCSET), 2006, Lviv-Slavsko, Ukraine (2006).

L. Pegoraro, Derecho Nacional, Derecho Internacional, Derecho Europeo: la circulación horizontal y vertical entre formantes, Actas del V Congreso Nacional de Derecho Constitucional, México (2013).

P. Gottschalk, Knowledge Management in the Professions: The Case of IT Support in Law Firms, en 33rd Hawaii International Conference on System Sciences, Hawaii (2000).

Yadira Alarcón \& Luis Miguel Hoyos, El Estado de cosas inconstitucional en el desplazamiento forzado y su incidencia en el derecho fundamental de la infancia y la adolescencia a tener una familia en Colombia, en La Constitución 20 años después. Visiones desde la teoría y la práctica constitucional, Pontificia Universidad Javeriana, Bogotá (2011).

\section{Artículos de revista}

A. L. Vélez, Salud y enfermedad: la contribución de la Corte Constitucional de Colombia, 17 Hacia la promoción de la salud, No. 2, 91-109 (2012).

A. M. Gutiérrez, Tendencia actual de amparo en materia de derechos económicos, sociales y culturales en la jurisprudencia de la Corte Constitucional, Revista Derecho del Estado (2010).

C. M. Molina, El rol institucional de la Corte Constitucional 28 Revista de Derecho, Universidad del Norte, 213-242 (2007).

D. Olarte \& J. González, La influencia de los pronunciamientos de organismos internacionales en la jurisprudencia de la Corte Constitucional Colombiana, 12 Materia de Derechos Económicos, Sociales y Culturales DESC. International Law Revista Colombiana de Derecho Internacional, 253-300 (2008).

D. F. Franco, La función hermenéutica constituyente de la Corte Constitucional. Una mirada a la luz de la conformación jurídica de la familia, 26 Díkaion, No. 2, Universidad de la Sabana (2012).

D. Mendieta, La acción pública de inconstitucionalidad: a propósito de los 100 años de su vigencia en Colombia, 120 Vniversitas jurídica, 61-84 (2010). 
D. Sanclemente \& A. Hinestrosa, Novedades: trascendencia de las redes sociales en el ordenamiento jurídico colombiano y la afectación de los derechos fundamentales sentencia T-260 del 29 de marzo de 2012, Corte Constitucional de Colombia, No. 9, 305-311 (2012).

E. Leiva, La corrección moderada de los padres y el derecho al libre desarrollo de la personalidad de sus hijos a la luz de la jurisprudencia constitucional, 46 Revista de Derecho Privado (2011).

F. Werro, La jurisprudence et le droit comparé, 20 Perméabilité des ordres juridiques, 165-ss. (1992).

G. A. Durango, Los movimientos sociales desde la perspectiva de las mujeres y pueblos indígenas. Un análisis desde la jurisprudencia de la Corte Constitucional colombiana, 37 Revista de derecho (2012).

H. A. Olano, Tipología de nuestras sentencias constitucionales, Vniversitas, Pontificia Universidad Javeriana (2004).

J. C. Lancheros, El precedente constitucional en Colombia y su estructura argumentativa. Sintesis de las experiencias de un sistema mixto de constitucionalidad a la luz de la Sentencia T-292 de 2006 de la Corte Constitucional, 1 Díkaion, No. 21, Universidad de la Sabana, 159-186 (2012).

J. P. Sarmiento, La modulación de sentencias como medio para articular la oportunidad política de la Corte Constitucional Colombiana. El caso de las parejas del mismo sexo, 37 Revista de Derecho Universidad del Norte (2012).

Sentencias de la Corte Constitucional con efectos reparativos, entre el Juez Administrativo y el Juez Constitucional, 121 Vniversitas, 161-192 (2010).

L. M. Escobar, El uso del precedente extranjero por parte de la Corte Constitucional colombiana, 13 International law Revista Colombiana de Derecho Internacional, 391-409 (2008).

L. R. Gómez, El control constitucional en Colombia sobre el inhibicionismo de la Corte Constitucional en los 100 años del control de la acción pública, 122 Vniversitas Jurídica, 169-212 (2011).

M. Londoño, Derechos de las parejas del mismo sexo Un estudio desde la jurisprudencia de la Corte Constitucional Colombiana, 11 Opinión Jurídica, No. 22, 45-64 (2012).

P. Lagrand, The Impossibility of Legal Transplants, Maastricht Journ. Eur. and Comp. Law (1997).

P. P. Vanegas, La Constitución colombiana y los estados de excepción: veinte años después, 27 Revista Derecho del Estado, 261-290 (2011)..

P. A. García, J.O. Agurrie. \& M. Albarracín ¿A quién le habla la Corte Constitucional colombiana? El juez y el auditorio universal. 39 Revista Facultad de derecho y ciencias políticas, No. 110, 77-95 (2009).

S. Insignares \& V. Molinares, La dignidad humana: incorporación de la jurisprudencia del Tribunal Europeo de Derechos Humanos por la Corte Constitucional Colombiana, 36 Revista de Derecho (2011). 


\section{Documentos electrónicos}

Consejo General del Poder Judicial. Centro de Documentación Judicial (Cendoj). Disponible en http://www.poderjudicial.es/cgpj/es/Temas/Documentacion_ Judicial/El_Centro_de_Documentacion_Judicial__Cendoj__

Corporación Excelencia en la Justicia. (2013). ¿Quiénes componen las Altas Cortes en Colombia?. Disponible en: http://portales.puj.edu.co/ftpcentroescritura/ Recursos/Normasapa.pdf

Corte Constitucional Colombiana. (2013). Relatoría. Disponible en: http://www. corteconstitucional.gov.co/relatoria/

Council of Europe (Committee of Ministers). (1995). Recommendation No. R (95) 11. Disponible en: http://www.raadvst-consetat.be/?action $=$ doc\&ydoc $=751$

D. Sanclemente \& X. Poveda, "Descubra quiénes componen las Altas Cortes en Colombia”. La República (7 de octubre de 2013). Disponible en: http://www. urosario.edu.co/urosario_files/f6/f6868318-7a7a-4320-bfe5-7706fc5c10c7.jpg

Sala Administrativa del Consejo Superior de la Judicatura, Sistema de Información Doctrinario y Normativo (SIDN). Disponible en http://200.26.152.57/sidn15/ bibliotecaweb (2003).

Sala Administrativa del Consejo Superior de la Judicatura, Tecnologías de la Información y las Comunicaciones (TIC) para la justicia. Plan TIC para la Rama Judicial. Disponible en: http://www.ramajudicial.gov.co/csj/ downloads/UserFiles/File/ALTAS CORTES/CONSEJO SUPERIOR/UDAE/ publicaciones/2011 CAP $\%$ C3\%8DTULO 5-TECNOLOG $\%$ C3\%8DAS DE LA INFORMACI\%C3\%93N Y LAS COMUNICACIONES.pdf (2012).

Sala Administrativa del Consejo Superior de la Judicatura, Centro de Documentación Socio-Jurídica de la Rama Judicial - Cendoj. Disponible en: http:// www.ramajudicial.gov.co/csj/publicaciones/csj/subcategoria/345/847/ Informaci $\%$ C3\%B3n-General (2012).

Sala Administrativa del Consejo Superior de la Judicatura, Plan estratégico tecnológico de la Rama Judicial. Disponible en: http://www.ramajudicial.gov.co/csj// noticias/csj/750/La-Sala-Administrativa-adopta-el-Plan-Estrat $\% \mathrm{C} 3 \%$ A9gicoTecnol\%C3\%B3gico-de-la-Rama-Judicial (2012).

Sala Administrativa del Consejo Superior de la Judicatura, Centro de Documentación Judicial. Disponible en: http://saidoj.ramajudicial.gov.co (2013).

Systems and software engineering -- Vocabulary. (2010). ISO/IEC/IEEE 24765:2010(E), 1-418. doi: 10.1109/ieeestd.2010.5733835 